\title{
Políticas coloniais e sociedade angolana nas memórias e discursos do escritor Raul David
}

Washington Santos Nascimento*

Resumo: Este artigo analisa a trajetória do ex-assimilado, político e escritor angolano Raul Mateus David. Pretende-se entender como ele viveu, pensou e escreveu sobre as políticas de assimilação colonial de Portugal em Angola e a sociedade angolana antes e depois da independência. Para tanto faremos uso de suas memórias e discursos presentes em entrevistas e obras literárias.

Palavras-chave: Angola. Assimilados. Sociedade. Memória. Literatura.

Os assimilados foram angolanos que durante o governo salazarista português em Angola (1926-1974) utilizaram-se do Estatuto do Indigenato (1926-1961) e seus documentos complementares, para conseguirem um status legal de civilizado, que os afastava do trabalho compulsório, além de permitir que trabalhassem nos órgãos da administração metropolitana, terem autonomia para deslocar-se dentro da colônia, solicitar carteira de motorista, direito a voto etc., possibilitando assim alguma ascensão econômica e social ${ }^{1}$. Eles se dividiam em duas categorias diferentes, em função das origens, os "antigos assimilados" da qual faziam parte os descendentes da antiga elite nativa (os crioulos) e uma nova camada intermediária, os "novos assimilados", que não tinham vínculos familiares, como

" Doutor em História Social pela Universidade de São Paulo - USP. Professor de História da África do Instituto de Filosofia e Ciências Humanas (IFCH) da Universidade do Estado do Rio de Janeiro (UERJ). E-mail: washingtonprof@ gmail.com

Anos 90, Porto Alegre, v. 23, n. 44, p. 265-289, dez. 2016 
as elites crioulas existentes, sobretudo em Luanda, haviam conseguido o estatuto depois dos anos quarenta e apesar de não se verem nem atuarem como grupo, possuíam alguns elementos em comum, como a origem rural, serem "pretos" e terem adquirido escolaridade formal nas missões religiosas (sobretudo, protestantes) ${ }^{2}$.

Os "novos assimilados" faziam parte de uma pequena elite letrada que atuava nas franjas do sistema colonial e das famílias crioulas, como burocratas do terceiro escalão da administração portuguesa, professores, gráficos, enfermeiros, contabilistas, pequenos comerciantes... No processo de luta anticolonial cerraram as fileiras, sobretudo do Movimento Popular de Libertação de Angola (MPLA), bem como adentraram pelo mundo literário, escrevendo contos, romances e poesias. Fizeram parte deste grupo os políticos e escritores como Manuel Pedro Pacavira (Golungo), Uanhenga Xitu (Ícolo e Bengo), Jacques Arlindo dos Santos (Libolo), Adriano Sebastião (Ícolo e Bengo) e o objeto de nossa análise neste artigo Raul Mateus David (Benguela).

David foi um personagem de fronteira, produto da interação cultural produzida nos entre-lugares da sociedade colonial, entre as culturas portuguesas e angolanas, o campo e a cidade, o mundo não letrado e letrado ${ }^{3}$ Nas palavras do também escritor David Mestre, um "[...] assimilado clássico, transmigrante de culturas, lusófono sem desprimor das referências umbundu pela síntese das interpretações” (MESTRE, 1985, p. 104). Sua história nos possibilita entender como um assimilado viveu, pensou e escreveu sobre a sociedade colonial e as políticas de assimilação colonial de Portugal em Angola. Além disso, de maneira mais tangencial como ele, ligado ás estruturas do colonizador, lidou com os desafios de imaginar a nação angolana em sua produção escrita e oral ${ }^{4}$.

Seus depoimentos e obras literárias, entendidas aqui enquanto expressões de uma memória coletiva (ou social) se referem ao período compreendido entre os anos trinta e setenta do século $\mathrm{XX}^{5}$. Momento este marcado por uma maior presença do colonialismo português no campo angolano onde David nasceu, com a imposição das culturas obrigatórias, desapropriação de terras dos nativos, estabelecimento de formas de servidão... gerando tensões e resistências no mundo 
rural angolano, como a revolta nas terras algodoeiras da Baixa de Kassange e os conflitos existentes com maior densidade a partir de 1961, nas plantações de café do noroeste ${ }^{6}$.

Havia também uma maior presença de colonos brancos nas cidades, sobretudo Luanda, saltando de 78.826 brancos em toda Angola no censo populacional de 1950 para 172.529 na nova pesquisa feita no ano de 1960, um aumento de mais de 100\%. Ainda neste censo, registrava-se que os falantes de língua Umbundu, grupo originário de David, correspondia a $38,1 \%$ da população angolana nativa registrada pelos orgãos administrativos portugueses (CONCEIÇÃO NETO, 2003).

Outra informação importante deste registro censitário é em relação à quantidade de assimilados, categoria a qual Raul David pertencia, em torno de 100.000 pelo censo de 1960, o que significava 2,5\% do total da população recenseada, 4.145.266 (MOURÃO, 1997). Apesar de poucos significativos, o fato de terem sido formados nas missões protestantes e assim terem acesso ao mundo das letra os colocava no centro do poder e da resistência ao colonialismo português.

E justamente esta elite letrada que construiria instrumentos de resistência ao colonizador, como as revistas Mensagem, Cultura, Angola etc. e os panfletos que circulavam pelos bairros populares de Luanda, como o bairro operário. Além de se associarem aos movimentos de contestação ao colonialismo tal qual a União dos Povos do Norte de Angola (depois União dos Povos de Angola - UPA), a Frente Nacional de Libertação de Angola, (FNLA), o Movimento Popular de Libertação de Angola (MPLA), do qual David foi um dos principais nomes, e mais tarde a União Nacional para a Independência Total de Angola (UNITA). Movimentos estes que somados irão conseguir a independência de Angola em 1975.

Por fim, é possível pensar David como uma testemunha que reflete e revela sua época, como uma espécie de receptáculo de diferentes correntes de pensamento e movimentos que a narrativa de sua vida torna mais palpável. É o que passaremos a ver a seguir. 


\section{Raul Mateus David: alguns apontamentos biobibliográficos}

Político e escritor angolano, Raul Mateus David nasceu em 23 de abril de 1918, na província de Benguela, na cidade da Ganda, $\infty$ Angola. Alfabetizado por sua madrinha portuguesa, fez ensino secundário no Seminário Menor do Sagrado Coração de Jesus, ligado aos padres do Espírito Santo, no Galangue (1932-1938). Saiu do Seminário em 1938, com 19 anos de idade, no 6o ano, solicitando o bilhete de assimilado (o "atestado de assimilação"). Depois disso foi trabalhar na administração civil da Gamba, partindo para uma casa comercial de Benguela onde aprendera contabilidade. Anos mais tarde dirigiu-se para um escritório contábil no caminho de Ferro de Benguela, de onde foi para Huambo, Mampesa e uma série de outros lugares, onde, segundo ele, teve contato mais próximo com a "vida indígena" (nativa).

Começou a publicar tarde, por volta dos cinquenta e seis anos. Suas obras se destacam pelo estudo do passado colonial nas zonas interioranas de Angola e a denúncia do colonialismo português, como em Colonizados e colonizadores, publicado em 1974, Escamoteados na Lei de 1977; Contos Tradicionais da Nossa Terra (I) em 1978, Narrativas ao acaso de 1979, Contos Tradicionais da Nossa Terra (II) de 1981, Cantares do Nosso Povo, publicado em 1988; Ekaluko Lyakwafeka: brado patriótico de 1988, Crónicas de Ontem para Ouvir e Contar de 1989 e por fim em 1997, Da Justiça Tradicional dos Umbundos.

Além disso, foi um dos membros fundadores da União dos Escritores Angolanos (UEA) e adepto do Movimento Popular de Libertação de Angola (MPLA), sendo adido cultural na Embaixada de Angola na Zâmbia, nos fins dos anos oitenta e nos anos noventa e dois mil exerceu a função de Direção provincial da Cultura e na Televisão Pública de Angola. Até os últimos anos de sua vida manteve-se ativo, atuando como ator no filme Comboio da Canhoca de 2004 ou ainda colaborando ora com a cessão de poesias para serem musicadas ou mesmo colaborando em pesquisas distintas como, por exemplo, sobre os judeus em Angola.? 
Faleceu em 20 de Fevereiro de 2005 em Lobito, província de Benguela. Quando de sua morte o escritor Boaventura Cardoso (2005), então ministro angolano da Cultura, disse que era uma biblioteca que desaparecia, uma enciclopédia viva do passado colonial. Por conta de sua morte deixou ainda duas obras inconclusas, Benguela no espaço e o tempo e Baronesa entre rios. ${ }^{8}$

Em grande parte falou através de suas obras literárias, apesar de conceder algumas entrevistas eventualmente. ${ }^{9} \mathrm{O}$ depoimento mais significativo, pelo menos localizado por nós, foi o dado a Michel Laban, ao qual passaremos a discutir a seguir, para depois fazermos uma discussão sobre sua obra literária. Tanto a entrevista quanto as obras literárias podem ser entendidas enquanto discursos de um homem extremamente vivido (seu primeiro livro foi publicado quando já tinha 56 anos e dera a entrevista para Laban, com setenta anos de idade), produzidos em um contexto específico: guerra anti-colonial, guerra civil e a necessidade de imaginar uma nação para Angola.

\section{Ser um assimilado, viver uma política de assimilação colonial}

A entrevista concedida por Raul David foi realizada em 05 de Abril de 1988 por Michel Laban e fez parte do primeiro livro organizado por ele e dedicado a Angola, publicado em 1991, onde também conta com entrevistas de escritores "mais velhos" tais como Óscar Ribas, Luandino Vieira, Manuel dos Santos Lima, Uanhenga Xitu e Boaventura Cardoso ${ }^{10}$. Trata-se de uma entrevista dada mais de 20 anos atrás, mas que ainda foi pouco estudada, além disso, a despeito de ter sido uma figura pública de destaque no cenário angolano, excetuando-se a série de entrevistas dadas a Maria da Conceição Neto (2012) no ano de 1994, desconhecemos outro depoimento que tenha sido tão rico quanto aquele dado e publicado por Laban.

Toda a entrevista foi marcada por um "conflito" entre o que o entrevistador queria perguntar (questões ligadas a sua produção 
literárias e sobre personagens da história angolana, como os contratados, funantes e aviados) e o que David queria dizer (sobre suas trajetória e ligação com o universo português e nativo). Assim o que temos ao final é um grande depoimento da vida e obra de David.

A primeira pergunta de Laban dizia respeito ao que era realidade e ficção em seus livros Colonizados e Colonizadores e Escamoteados na Lei. Segundo David, "[...] os contos que eu escrevo têm sempre base no convívio com pessoas, em imagens vividas por mim próprio ou, então, na narrativa que oiço [sic] de mais velhos" (DAVID apud LABAN, 1991, p. 49). Assim ele procura evidenciar suas obras enquanto representações de uma memória coletiva, destacando para tanto o "respeito pela cadeia" e o "respeito pela transmissão", um dos elementos essenciais da memória africana (HALBWACHS, 2004; HAMPATE BÂ, 2010).

Entretanto, como um personagem de fronteira, David também salientou que não esquecera o que aprendera nas escolas portuguesas, "[...] eu, de minha parte, não fugi à regra escolástica que me foi estabelecida, porque não tenho outra maneira de escrever, não tenho outra maneira de me fazer entender" (DAVID apud LABAN, 1991, p. 50). Por outro lado, "[...] tenho que ter uma expressão africana, na minha maneira de narrar. Não posso ser acadêmico em demasia" (DAVID apud LABAN, 1991, p. 50). Neste sentido concordamos com Mary Louise Pratt (1999), que se os povos colonizados não podem determinar facilmente aquilo que vem da cultura dominante, eles efetivamente determinam o que (e como) absorvem em sua própria cultura, bem como de que forma será utilizada. David define-se como sendo um ex-assimilado e fazendo uso dos binarismos português-não português, vantagem-desvantagem, ventura-desventura, dá mais informações sobre este estatuto:

Eu fui assimilado. $\mathrm{O}$ assimilado teve vantagens e desvantagens. Vou-lhe contar quais eram as vantagens dos assimilados. A vantagem era poder ir ao cinema onde estavam brancos quando eles aceitavam - viajar numa carruagem de $2^{\underline{a}}$ classe, com os brancos, estar no mesmo restaurante, mas isso era tudo fictício, num certo ponto... Porque havia restaurantes de luxo onde o assimilado não entrava por incapacidade 
financeira e até pelo esnobismo dos frequentadores desses lugares (DAVID apud LABAN, 1991, p. 54).

A mensagem de David é direta, ele foi assimilado, não era mais. Em um contexto de formação de uma nação, era importante deixar claro a recusa da assimilação colonial. Ser assimilado era ter um estilo de vida europeu, o que incluía ir ao cinema, caso os brancos aceitassem $^{11}$. Em sua fala é possível perceber o racismo enquanto uma fronteira social difícil de ser transposta, sobretudo se a ele estivesse associado a desigualdade econômica e revela um contexto no qual Portugal solidificou um sistema eficiente de dominação e controle político, baseado tanto na existência de categoriais legais fortemente marcadas pela burocracia, quanto pelo racismo, articulando essas duas dimensões, a burocracia e a raça para melhor organizar politicamente e dominar os angolanos ${ }^{12}$.

Para ele a principal vantagem era de que sendo "cidadão" poderia defender-se nos tribunais coloniais, diferentemente do "indígena". $\mathrm{O}$ argumento usado por ele de que tal estatuto tornava quem o conseguia um cidadão com direitos e em situação de igualdade jurídica perante os portugueses. De certa forma esta ideia era a reprodução do que de alguma maneira era amplamente divulgado pelos ideólogos portugueses como Adriano Moreira (1956) e não toca na questão principal, que era o fato de ser um "assimilado" o afastava do trabalho obrigatório instituído pelo Estatuto do Indigenato aos não cidadãos, os "indígenas", e esta sim era uma das principais razões para se buscar tal estatuto.

Sobre as "desvantagens", disse ele que a principal era que mesmo o assimilado tendo a mesma instrução que o europeu, nunca ascenderia a lugares de governança, tendo sempre uma posição subalterna. David vai além ao dizer que o assimilado tinha um "ordenado de miséria" e uma "velhice ruim", estava inclusive em condição pior do que os nativos ("indígenas") pois pelo menos estes tinham a sua propriedade e o seu gado, vivendo "economicamente desafogado". Sua fala distorce a realidade angolana do período, pois a realidade de grande parte desta população nativa era de penúria social e econômica.

David continua destacando que entre 1910 e 1926, durante a República Portuguesa, havia o estatuto de "civilizado" para "[...] 
qualquer preto que falasse português e soubesse ler e escrever" (DAVID apud LABAN, 1991, p. 54-55). Entretanto depois da ditadura salazarista e do Estatuto do Indigenato (de 1926), este estatuto ("civilizado") foi revogado, no lugar dele aparecia o "assimilado", fazendo com que aqueles que quisessem manter seu status legal tivessem de passar pelas démarches novamente.

Uma alteração significativa neste contexto foi a chegada de novos colonos portugueses nos anos quarenta, registrado assim por ele: "[...] quando a família portuguesa cresceu, cá dentro, cerca dos aos 40, houve a assimilação" (DAVID apud LABAN, 1991, p. 56). Cláudia Castelo (2007) destaca que em 1940, 50,56\% da população branca estava nas cidades; em 1950, esta porcentagem passou para $57,66 \%$ e, em 1960, excedia os 60\%, ou seja, houve um crescimento de $10 \%$ em dez anos. As localidades com maior presença europeia eram Luanda, Huambo, Benguela, Huíla, Bié, Moçamedes e Cuanza-Sul, sendo que a capital de Angola, em 1950, apresentava um crescimento de mais de 108,52\% da população oriunda de Portugal.

Em 1954, o Estatuto do Indigenato é reformulado, criando ainda mais dificuldades para a obtenção do Bilhete de Assimilado, além de tornar esta condição frágil, já que, como salienta Nascimento (2013), poderia ser revogada a qualquer momento, ao sabor das autoridades administrativas. Por esta razão, ele pode ser entendido como o resultado de um esforço empreendido por Portugal para proteger os portugueses menos qualificados da concorrência interna com os nativos. E é sobre o estatuto de 1954 que David vai mais claramente responder o que tinha sido anteriormente perguntado por Laban, ou seja, quais as prerrogativas para se tornar um assimilado:

Mais tarde, veio então o atestado de assimilação, nos anos 50 . Aí então... Era preciso bilhete de identidade - mas, para obter o bilhete de identidade, era preciso obter a cidadania... E isso então foi escabroso... Aí foi a humilhação total do negro: o indivíduo tinha que preparar uma série de documentos, uma coisa doida... Certidão de idade, habilitações literárias, isto é, a $4^{\underline{a}}$ classe, diploma, atestado de residência, atestado de comportamento moral e civil - dado pelo administrador do concelho -, veja bem... E depois, documento militar - e 
para obter esse documento militar, se era indígena, era preciso pagar $\mathrm{x}$ impostos, segundo a idade que ele tinha, era o imposto indígena, e só depois é o que lhe passavam o documento militar. Depois, registro policial, registro criminal! (DAVID apud LABAN, 1991, p. 56).

$\mathrm{Na}$ construção discursiva expressões enfáticas como "humilhação total", "série de documentos", "sete documentos", "Isso é horrível!”. A “humilhação” se dava pelo excesso burocrático desse processo, que por um lado tinha como pressuposto básico evitar o próprio sucesso da assimilação, pois "Se todos os colonizados se tornassem colonizadores, quem colonizaria?” (MEMMI, 1989, p. 8). Por outro lado, essas exigências serviam para "enquadrar", de maneira discriminatória, os futuros assimilados ${ }^{13}$.

A razão para tais entraves e dificuldades na concessão do documento de assimilado pode ser explicada, também, pelo fato de que os próprios colonos temiam a concorrência daquela elite local. Castelo (2007) e Conceição Neto (2000) mostram que para proteger os imigrantes portugueses menos preparados as autoridades metropolitanas mostraram-se extremamente rigorosos no exame das condições exigidas para a concessão do estatuto aos angolanos.

Para romper essas dificuldades, aqueles que queriam se tornar assimilados elaboraram uma série de mecanismos de resistências à violência do colonialismo português. Para isto falsificavam documentos ou mesmo habitações para que fossem considerados "civilizados" e assim terem as supostas vantagens correspondentes a esse estatuto. Como salienta David havia a revista das autoridades coloniais na residência dos pretendentes, mas as autoridades eram ludibriadas porque havia sempre um parente que emprestavam móveis, utensílios domésticos etc. Adriano Sebastião (1993), em seu livro de memórias, também descreveu a visita de um desses inspetores em sua casa no ano de 1953, onde teriam ido para comprovar que suas cunhadas (que viviam com ele) tinham condições para conseguir o estatuto, segundo ele os funcionários arbitrariamente mandaram levantar os colchões das camas para ver se elas não era de capim. Maria Conceição Boavida em depoimento dado a Fernando Correia (2009) diz que este burocrata português ia à casa do candidato para 
ver como a família em questão vivia, ou seja, como é que comia, como se vestia. Já Fernando Mourão (2006) registra o depoimento de um pastor protestante, Sebastião Paes Domingues, que trabalhou nos musseques de Luanda. Afirma este pastor que várias vezes ele emprestou a sua mobília a candidatos para que assim estes pudessem enganar as autoridades coloniais. O ex-bispo da Igreja Metodista, Emílio de Carvalho, também relatou em trabalho de Ledson Chagas (2009), que sua família conseguiu ludibriar as autoridades pois ele não dormia em camas, mas sua mãe arrumou o quarto de uma forma no dia da visita, quando o funcionário apareceu pensou estar diante de uma "casa portuguesa” em Angola.

Voltando à entrevista de David ele ressalta que mesmo ante a esta dificuldade, tanto aqueles que conseguiram o estatuto de assimilado e seus filhos tinham algum tipo de proteção, pois "ninguém bulia com eles”. Mas era fato também o peso que o processo de assimilação, ou seja, quanto mais jovem se tornava um assimilado, maior era a perda do domínio sobre a língua nativa, bem como a alienação em relação à situação dos angolanos tipificados como "indígenas".

Para David, o resultado da política de assimilação foi a segregação existente dentro da sociedade angolana, pois a posição de indígenas e assimilados separava as pessoas. "[...] Inclusivamente houve assimilados que aproveitaram mal a sua posição de assimilados - ficaram iludidos, julgando naturalmente que eram brancos" (DAVID apud LABAN, 1991, p. 60). Entretanto ele era diferente:

Eu considerei-me sempre negro. Evidentemente, com um substrato social respeitando a minha posição, mas humanizando-me com os meus irmãos. Eu até lhes dizia 'Meus amigos, quando vocês me veem dar com os brancos, é para vossa defesa! Porque se eu não estiver ao pé dos brancos, vocês não tem defesa nenhuma. E eu é que vos defendo...' (DAVID apud LABAN, 1991, p. 60).

$\mathrm{Na}$ resposta ele faz uso da expressão "negro", até então ele se referia a dimensão racial "pretos". Mas esta categoria política não significava homogeneidade, pois ele tinha uma "posição", um "substrato social" diferente, mas "humanizava-se" com os demais 
angolanos. A referência à negro (e talvez a negritude) também foi uma forma de evidenciar o fato de que ser assimilado não era "vender-se" aos portugueses, mas sim utilizar-se de uma prerrogativa dada pelo colonizador para assim ter uma proteção social (e sobretudo jurídica) um pouco maior do que a dos “indígenas" e sobretudo lutar contra a dominação colonial ${ }^{14}$. David busca então reforçar a visão diz que estava do lado dos nativos e que por essa razão era respeitado por eles:

Senhor Raul, nós conhecemos muito assimilado, mas como você não conhecemos... Um homem que concebia a sua vida convivendo conosco, seus irmãos, e convivendo com os brancos - e fazendo respeitar-se nos dois lados - isto é muito difícil (DAVID apud LABAN, 1991, p. 61).

A entrevista continua com perguntas de Laban sobre personagens da sociedade angolana e de que maneira eles aparecem em suas obras, tais como o contratado, o funante, o aviado... além das ligações de David com o comércio e seus trânsitos pelo interior de Angola e termina com o depoimento de David, de que mesmo depois do fim do Estatuto do Assimilado essa distinção permanecera na sociedade angolana, fazendo com que muitos assimilados tivessem "velhices ruins" em função de seu comportamento durante o período colonial.

\section{A literatura de David: pensar e escrever a sociedade colonial, imaginar a nação}

A literatura de David faz parte de um conjunto de escritos que tem na reflexão sobre a sociedade colonial um dos seus elementos centrais. Nestas obras o narrador funciona, segundo Inocência Mata (2012), como griot, ou seja, um cronista dos eventos do cotidiano, fazendo uso de suas memórias e experiências individuais e coletivas. Desde grupo fazem parte nomes como Luandino Vieira, Manuel dos Santos Lima, Arnaldo Santos, Uanhenga Xitu, Pepetela, Boaventura Cardoso... e Raul David. 
Este conjunto de obras cumpre um papel formativo importante, em um contexto no qual a história de Angola, enquanto uma escrita científica produzida pelos próprios angolanos, ainda estava pouco ou não escrita. Assim temas da história local da primeira metade do século XX ressaltam nas obras de David como a imposição de culturas obrigatórias (sisal, café...), opressão e resistência ao colonialismo, formas de justiça nas sociedades tradicionais umbundo, missões e missionários no interior de Angola (sobretudo Benguela), as relações comerciais existentes e seus personagens como o aviante, funante, roceiro, contratado etc. Apesar disto David não tem merecido ao longo dos anos, muitas análises de sua produção literária, sendo tangencialmente citado ou referenciado por alguns pesquisadores e estudiosos ${ }^{15}$.

Como político-escritor-historiador podemos pensar David enquanto um literato que fez história e um historiador que fez literatura, por outro lado, as posições do homem político atravessaram todas as entrevistas e obras literárias analisadas. Como queria fazer-se entender usou no inicio de suas obras prólogos, "esclarecimentos" e citações. Desta maneira buscou direcionar o olhar do leitor para que este observasse o que ele desejava. O que não impede, entretanto, a existência de uma série de discursos diferentes e por vezes até divergentes, as polifonias, que se entrecruzam e se chocam nas suas obras, bem como na entrevista analisada anteriormente.

Colonizadores e Colonizados foi o seu primeiro e até hoje mais famoso livro. Trata-se de uma série de relatos sobre a colonização portuguesa e sociedade em Angola e São Tomé na primeira metade do século $\mathrm{XX}^{16}$. Em grande parte as histórias se passam na região de Benguela e trazem a ideia de um universo social cindido entre colonizadores e colonizados, brancos e negros ${ }^{17}$. O livro já em sua versão definitiva (do ano de 1984), é composto de 22 contos. Em grande parte os personagens são homens de fronteira, ambíguos, móveis, que transitam por Angola e São Tomé que se misturam com as pessoas e estruturas locais. O que para Laura Padilha (2006) é uma constante na ficção angolana produzida entre os fins do século XX e início do XXI no qual os "os sujeitos produtores de textos" buscavam encetar uma espécie de "viagem por sua alteridade", daí a 
construção de histórias onde os trânsitos, travessias, deslocamentos, andanças... faziam-se recorrentes.

Em Colonizados..., a caracterização de uma sociedade plural, mais cindida, onde personagens de fronteira como Manuel Karitoko teriam sempre um destino ruim caso esquecessem suas raízes:

Agora destribalizado, o nome da sua terra passara a ser um símbolo denominativo, tinha como única valia a identificação pessoal na caderneta do imposto indígena, pois todo homem tem terra, onde nasceu.

Os parentes distantes seriam assuntos de ocasião, porque na vida de Manuel Karitoko o que contava agora era o trabalho de todos os dias, por semanas a fio, meses e anos, sem saldo positivo forrado no canto da mala.

[...] perdera-se como tantos outros no turbilhão absorvente da cidade (DAVID, 1984, p. 34).

A mensagem que parece está claro nesta obra de David é de que mesmo em uma realidade de personagens plurais, vivia-se uma sociedade segregada, onde o meio termo não era uma boa escolha naquele contexto de violência e injustiça ${ }^{18}$. O que pode ser visto no último conto do livro, Rescaldo de Fim-de-Ano que conta a história do português Eduardo de Morais que falava bem o quimbundo e tinha acesso aos ritos daquela comunidade ${ }^{19}$. Ele vivia maritalmente com duas angolanas, quando foi roubado. No inquérito policial estabelecido pela autoridade portuguesa local (o "chefe do posto"). David coloca na boca de seus personagens a crítica aos processos de mistura e os lados daquela situação colonial. Para o chefe do posto "[...] se não estivesse tão promiscuído com pretos nada disso teria acontecido" (DAVID, 1984, p. 180). Bem como mulheres angolanas dizem para as esposas do Português, depois destas serem injusta e violentamente torturadas, que era "[...] muito bem feito para elas. Tiveram o troco de comerem bem. Agora, daqui para diante, ficam sabendo que branco não tem amigo preto" (DAVID, 1984, p. 180). Assim termina o livro com uma mensagem clara a cerca de uma 
sociedade profundamente diversa, com identidades, múltiplas e plurais, trânsitos, mestiçagens e misturas de diversas ordens, mas cindidas entre o colonizador e o colonizado, na qual o angolano teria que escolher um lado.

Seu segundo livro Escamoteados na Lei traz contos inspirados em situações reais de uma Angola colonial profundamente marcada pela violência do colonizador e pela resistência dos colonizados. Nesta obra a preocupação com os fatos históricos é maior do que a própria criação literária. $\mathrm{Na}$ edição de 1980, Raul David inclui um "esclarecimento", onde assume a importância do trabalho de "resgate histórico", das ações do MPLA no qual era ligado, bem como assume a sua condição de ex-assimilado e o seu papel naquele contexto pós-independência.

Povo colonizado que fomos, mesmo quando revestidos da frágil capa de 'ASSIMILADOS', foi-nos vedada (isso é verdade) a porta da narrativa histórica. Deste modo, foram-se extinguindo dados preciosos, com a morte dos velhos que os retinham na sua arca mental. Resta-nos, na medida do possível, salvar o que ainda existe (DAVID, 1980, p. 10).

Trata-se de um momento de imaginar uma nação angolana, o livro é de 1977 e a independência se dera em 1975, no qual não seria possível deixar as marcas da colonização de fora, mas a recusa da assimilação e a busca pelas tradições (e raízes) seriam o norte a partir do qual esta nação deveria ser construída, possibilitando assim princípios de uma "camaradagem horizontal" e um "nós coletivo" $20 .^{2}$.

Os contos do livro tem um caráter de denúncia no qual destaca a tomada das terras dos nativos, imposição de culturas agrícolas obrigatórias, "leis de papel”, injustiças com acusações falsas de crimes... A violência do colonizador é ressaltada com o claro propósito de chocar o leitor, como por exemplo em Chico das Cabras no qual o protagonista foi injustamente preso e torturado, "[...] palmatoado nas mãos e pés; as costas foram-lhe cortadas a chicotadas de cavalo-marinho pelo próprio chefe, enquanto dois cipaios o bastonavam à mangueirada" (DAVID, 1980, p. 48). Além 
disso, resistências igualmente dramáticas, como no caso de descrito em Neketela, onde o personagem que dá titulo ao texto, diante de mais uma situação de trabalho obrigatório, utiliza-se de um enxó (espécie de enxada pequena) decepando quatro de seus dedos.

Como no livro anterior David descreve ao longo dos seus 13 contos uma sociedade dual, marcadamente cindida entre colonizadores e colonizados, como se vê por exemplo no conto Patriotas que relata a história de Amandio, mais conhecido como gigante, filho de português com uma angolana. Órfão de mãe, ao perder o pai será criado pelos seus irmãos mulatos. Gigante falava umbundu e por ser motorista estava em todos os lugares. David procura evidenciar um sujeito mestiço, de misturas e trânsitos. Mas mesmo assim, este personagem tinha um lado naquela situação colonial:

De boas falas, estava em todos os meios, quer de brancos funantes ou exportadores, quer de pretos indígenas ou assimilados. Quer era aldrabarão, toda a gente também o sabia. Que era vigarista, sabiam-no seus credores ou amigos a quem pediam letras de favor sem satisfazer muitas delas. No fundo e no restos, as pessoas, umas mais outras menos, gostavam dele. Porém, estava ainda por descobrir a sua última qualidade: DELATOR DA PIDE (DAVID, 1980, p. 48).

Ser delator da temida Pide (Polícia Internacional e de Defesa do Estado) que perseguia, prendia e torturava os africanos contrários a colonização portuguesa era a pior posição que um angolano ou português poderia ter, neste caso David reitera que o fato de que Amandio ("Gigante") ser um personagem, que transitava entre espaços e pessoas, o tornava ainda mais uma pessoa perigosa, "Gigante, camionista transitando por estradas, conhecedor de matas e quimbos, negros e costumes, língua e tendências, parecia tresloucado na denúncia aberta contra toda a gente" (DAVID, 1980, p. 48).

Os livros que se seguem a Escamoteados..., Contos Tradicionais da Nossa Terra (I), Narrativas ao acaso, Contos Tradicionais da Nossa Terra (II), Cantares do Nosso Povo e Crónicas de Ontem para Ouvir e Contar consolidam o viés histórico da produção literária de David. Nestes livros tenta-se mostrar aspectos da cultura tradicional 
de Angola, assumindo definitivamente a sua posição enquanto um pesquisador preocupado com o mundo rural angolano, com suas tradições e histórias. $\mathrm{O}$ apelo à tradição está anunciado no poema que antecede os contos de Crónicas...

Felizes os que souberam conservar as suas tradições deixadas pelos ancestrais. Felizes os que se não iludiram

Com o pregão insidioso Dos que se diziam portadores

Da mais humana civilização.

A realidade provou-nos dolorosamente

Os propósitos de quem africanamente Hospedámos em nossa casa (DAVID, 1989, p. 11).

Crónicas... compõe-se de uma série de micro contos que repetem quase sempre o mesmo padrão, a violência do colonizador, a reação do colonizado. Nesta obra ele deixa ainda mais explícito a posição de que mesmo aqueles que colaboraram (ou entraram) nas estruturas sociais e políticas do colonizador, mesmo assim estavam submetidos ao jugo colonial, como no caso do assimilado Capingana de Cavissamba, no conto de mesmo nome. Capingana tinha sido educado em uma missão protestante, possuía terras e de bom grado acolheu um português maltrapilho, cedendo-lhe trabalho. Como o tempo passa a ser roubado pelo europeu, e mesmo depois de denunciar a autoridade colonial nada foi feito. Afinal a palavra de um preto nunca valeria mais do que a de um branco.

Depois de uma lacuna de quase dez anos David publicou em 1997 o seu último livro, Da Justiça Tradicional dos Umbundus, que segue os mesmos padrões anteriores destacando a violência do colonizador ao submeter povos. Em grande parte é um aprofundamento do que ele já tinha feito em Colonizadores e Colonizados (escrito em 1974) pois em seus primeiro livro Colonizados... esta questão já tinha vindo a tona no conto O Juiz foi apenas testemunha e No banco dos Réus e representa um olhar sobre seu grupo social de 
origem, os umbundos. Encerrava-se assim um ciclo de obras que traziam um grande combate pela história de seu país e povo, mas também por sua identidade.

\section{Considerações finais}

Analisar a história do político e escritor Raul David é entender os lugares (e entre-lugares) da situação colonial, onde novas estratégias de estratégias de subjetivação (singular ou coletiva) e novos signos de identidade são formados. Por outro lado é também entender de que maneira estes personagens constroem estratégias de colaboração, "usos" e contestação ao sistema colonial, como fica evidenciado na sua entrevista pautada na distinção entre vantagens e desvantagens de ter sido um assimilado, na ideia de que "isso foi um jogo".

Suas memórias podem ser entendidas não só como um discurso político, mas também lócus de representação das situações de dependência e resistências das situações geradas pelo contato colonial, onde sacrifício e jogo, submissão e transgressão, obediência e rebelião, assimilação e expressão fizeram parte do "ritual antropófago" que ele como um assimilado se submeteu ${ }^{21}$.

Entretanto mesmo ele sendo um indivíduo hifenizado, ambivalente, híbrido, fruto de uma sociedade colonial na qual a simples oposição, entre colonizadores e colonizados, não dá conta de sua diversidade e pluralidade, suas entrevistas e produções literárias são frutos do momento das guerras (contra Portugal, depois guerra civil) e de construção de uma nação angolana que exigia dele um lado e convicções claras (e dualistas) em relação as políticas de assimilação e as cisões dentro da sociedade colonial. Ser menos dual, mais binário, no próprio exercício de imaginar e narrar o homem nacional, também fazia parte do jogo, a ser jogado naquele novo momento. Assim sendo é possível pensar Raul David, como um intelectual orgânico, ligado a seu grupo social de origem, viveu, pensou, "jogou" e escreveu sobre o colonialismo português em Angola e imaginou novas formações sociais, políticas e ideológicas para uma Angola, recém saída de uma dura luta anti-colonial ${ }^{22}$. 


\section{COLONIAL POLICIES AND THE ANGOLAN SOCIETY IN THE MEMOIRS AND SPEECHES OF THE WRITER RAUL DAVID}

Abstract: This article analyzes the history of assimilated, political and Angolan writer Raul David Matthew. It aims to understand how he lived, thought and wrote colonial assimilation policies of Portugal in Angola and the Angolan society before and after independence. For this we will make use of their memories and present speeches in interviews and literary works.

Keywords: Angola. Assimilated. Society. Memory. Literature.

\section{Notas}

${ }^{1}$ Apesar da terminologia "assimilado" já existir legalmente desde a Carta Orgânica de Angola de 1917, ainda no período republicano, estipulando a necessidade de um porte obrigatório do alvará, somente o regulamento do recenseamento e cobrança do imposto indígena (1931), durante o salazarismo, dizia de maneira mais clara e detalhada para Angola das condições que um "indígena” (nativo) teria que passar para se tornar um assimilado: 1) Ter abandonado inteiramente os usos e costumes da raça negra; 2) Falar, ler e escrever corretamente a língua portuguesa; 3) Adotar a monogamia; e 4) Exercer profissão, arte ou oficio compatível com civilização europeia, ou ter rendimentos que sejam suficientes para prover aos seus alimentos, compreendendo sustento, habitação e vestuário, para si e sua família. Uma discussão sobre os desdobramentos deste Estatuto pode ser encontrada em Cruz (2005).

${ }^{2}$ A distinção entre antigos e novos assimilados foi feita por Christine Messiant (2009). Mais recentemente Washington Nascimento (2013) aprofundou o debate sobre os novos.

${ }^{3}$ A ideia de entre-lugar é derivada de Homi Bhabha (1998), como um lugar de contato, mistura e da construção de novos processos culturais e identitários.

${ }^{4}$ Durante a colonização do continente africano houve modelos distintos de administração colonial, que grosso modo, pode ser definidas de duas maneiras; políticas de diferenciação praticadas por Inglaterra e Alemanha e políticas de assimilação seguidas por Portugal, França e Bélgica. Os primeiros defendiam uma administração indireta, que não substituía as estruturas pré-existentes e os chefes tradicionais reconhecidos, as culturas locais era vistas como "diferenciadas" e que por esta razão deveriam, na medida do possível, ser mantidas separadas (apartadas) das estruturas metropolitanas. Já os partidários das políticas de assimilação previam uma administração com certa integração política, ou seja, com o tempo e mediante certas reservas, os colonizados poderiam se 
tornar cidadãos com "plenos direitos" dentro da região colonizada, adquirindo o mesmo estatuto de qualquer cidadão metropolitano. M’Bokolo (2012); Betts (2010); Hernandez (2008).

${ }^{5}$ Consideramos como Maurice Halbwachs (2004), a memória enquanto uma reconstrução parcial e seletiva do passado a partir de determinados enquadramentos sociais, como a família, grupos profissionais, classes etc., servindo desta maneira como um elemento de coesão do grupo. Entretanto concordamos com James Fentress e Chris Wickham (1994) que há em Halbwachs um excesso de peso no olhar sobre as determinações coletivas e um desprezo sobre as dimensões individuais do ato de lembrar, apesar de não negar as influências do contexto social que cerca o indivíduo.

${ }^{6}$ Sobre a revolta de Baixa de Cassanje, caberia destacar a pesquisa de Aida Freudenthal (1995-1999).

${ }^{7}$ MORREU escritor angolano Raul David. AngoNotícias, 22 fev. 2005.Disponível em: <http://www.angonoticias.com/artigos/item/3907/morreu-angolano-raul -david>.

${ }^{8}$ MPLA consternado com morte do escritor Raúl David. ANGOP, 21 fev. 2005. Disponível em: <http://www.angop.ao/angola/pt_pt/noticias/politica/2005/1/8/ MPLA-consternado-com-morte-escritor-Raul-David,cdf2c41e-7505-4ada-9b89 -07feef7fa7df.html>. Acesso em: 23 jun. 2016.

${ }^{9}$ DAVID, Raul. É um erro crasso afirmar-se que a Kilapanga veio de S. Tomé. Jornal de Angola, 15 ago. 1993.

${ }^{10}$ Michel Laban nasceu na Argélia (Constantine) em 1946. Estudou Literatura Geral na Universidade de Argel e Espanhol e Português em Paris, França. Faleceu em 2008 em Paris. Ainda vivo realizou uma série de entrevistas com escritores angolanos, moçambicanos e cabo-verdianos publicando as mesmas entre os anos de 1980 e 2002.

${ }^{11}$ Nascimento (2013) mostra de que maneira os cinemas obedeciam a uma espacialização racial em Luanda, sendo que em alguns deles indígenas ou assimilados não podiam entrar, daí a referencia de David de que só poderia ir ao cinema "caso os brancos aceitassem".

${ }^{12} \mathrm{O}$ objeto central da obra de Hannah Arendt é a compreensão do totalitarismo, aprofundando, sobretudo, o caso soviético e o alemão. Mas ao apresentar um quadro completo da organização totalitária, a sua implantação, a propaganda, o modo como manipula as massas e de que maneira ele se apropria do Estado com vista à dominação total, usando para isso a dimensão do racismo e da burocracia. Arendt nos oferece suportes metodológicos importantes para entendermos realidades distintas como, por exemplo, o colonialismo Português na África. ARENDT, Hannah. Origens do totalitarismo. São Paulo: Companhia das Letras, 1989.

Anos 90, Porto Alegre, v. 23, n. 44, p. 265-289, dez. 2016 
${ }^{13}$ Os próprios defensores do colonialismo português, por exemplo, Afonso Mendes, português, aluno do Instituto Superior Ultramarino em sua dissertação $A$ Huila e Moçamedes descreve sobre o quadro social da região, (atual sul de Angola e hoje regiões de Huila e Namibe). Mendes defende que se houvesse uma simplificação na burocracia muitos se tornariam assimilados, "[...] estamos certos de que não haveria um indígena huilense em condições de ser assimilado que não diligenciasse obter o respectivo estatuto" (MENDES, 1958, p. 41).

${ }^{14}$ A Negritude foi um movimento político e cultural surgido na França a partir sobretudo de pessoas originárias das colônias francesas no Caribe. O termo surgiu em 1939, no poema lírico Diário de um retorno ao país natal, do antilhano da Martinica, Aimé Césaire, e foi cunhado para apreender a totalidade do mundo negro fundada na ideia de solidariedade racial, a partir da busca pela sabedoria ancestral, pela pujança da cultura africana e a ideia de anterioridade da África nas principais inovações do mundo contemporâneo (LE CALLENNEC, 2007, p. 455-546; HERNANDEZ, 2005, p. 131-156).

${ }^{15}$ Por exemplo, no famoso estudo de Manuel Ferreira, que ao analisar a história da literatura angolana, diz que Colonizados e colonizadores publicado em 1974, tratava-se de "[...] um testemunho fraterno do seu povo e uma visão de pendor cristão, excessivamente generoso na análise das relações entre colonizados e colonizadores" (FERREIRA, 1986, p. 58-59). Mais recentemente em seus estudos sobre a "ruralidade" na narrativa angolana do século XX, Ana Lopes de Sá dedicou a David apenas algumas referências em notas de rodapé, a despeito de praticamente toda a obra dele ser dedicada ao mundo rural angolano (LOPES DE SÁ, 2009).

${ }^{16}$ Nos contos há referência aos anos de 1910, 1913, 1941, 1943, e 1950 (DAVID, 1984).

${ }^{17}$ Como ele mesmo explica ao dizer que "[...] o mestiço e o assimilado quando tem comportamento europeu ou disfrutem de meios econômicos são chamados de brancos” (DAVID, 1984, p. 150). Ser branco não era uma questão de cor, mas sim de origem, comportamento social e de "lado" naquela sociedade dividida. ${ }^{18}$ É bem verdade que David relata também situações em que a injustiça foi contida, como em $A$ Lavadeira da Vizinha em que as "lágrimas sinceras" de Domingas a livraram de uma acusação injusta (DAVID, 1984).

${ }^{19}$ Ele tinha "[...] acesso aos 'tambos' dos caçadores, assistia à cerimônia da 'abertura dos fogos' nas grandes festas e participava até das makas, resolvendo-as quando chamado aos povoados”. Segundo David (1984), Tambos são compartimentos reservado aos apetrechos de caça, mas pode ser também onde se guarda objetos de cultos. Abertura do Fogo trata-se do ritual que antecede qualquer festa grande. Já Maka é uma palavra em quimbundo que quer dizer conflito, contenda (DAVID, 1994, p. 177). 
${ }^{20}$ Para Anderson (2008) a nação é uma comunidade imaginada porque, independentemente da desigualdade e da exploração efetivas que porventura possam existir dentro dela, a nação sempre é concebida como uma profunda camaradagem horizontal, a partir do qual se forma um grande "nós coletivo".

${ }^{21}$ Faz-se importante destacar a importância de Silvano Santiago (2000) para a discussão que ele faz sobre intelectuais, entre-lugares e culturas em situações de contato colonial.

22 Partimos da ideia de intelectual orgânico de Antonio Gramsci (2000) para entender David enquanto um pensador ligado às organizações políticas e culturais de seu grupo de origem, elaborando uma concepção ético-política-histórica que o habilita a exercer funções educativas e organizativas para assegurar a hegemonia social e o domínio estatal do grupo que representam.

\section{Referências}

ANDERSON, Benedict. Comunidades Imaginadas. São Paulo: Companhia das Letras, 2008.

ARENDT, Hannah. Origens do totalitarismo. São Paulo: Companhia das Letras, 1989.

BAKHTIN, Mikhail. Marxismo e filosofia da linguagem: problemas fundamentais do método sociológico na ciência da linguagem. São Paulo: Hucitec, 1986.

BETTS, Raymond F. A dominação europeia: método e instituições. In: BOAHEN, A. Adu (Coord.). História geral da África: África sob dominação colonial 18001935. v. VII. São Paulo: Cortez, 2010.

BHABHA, Homi. O bazar global e o clube dos cavalheiros ingleses. Rio de Janeiro: Rocco, 2011.

. O local da cultura. Belo Horizonte: Ed. UFMG, 2007.

CARDOSO, Boaventura. Morreu escritor angolano Raul David, autor de "Colonizados e Colonizadores”. Agência LUSA, 21 fev. 2005. Disponível em: <http;;// www.rtp.pt $/$ noticias/index.php?article $=153039 \& \mathrm{tm}=4$ \&layout $=121 \&$ visual $=49>$. Acesso em: 23 jun. 2016.

CARDOSO, Boaventura. Prefácio à $1^{\circ}$ Edição. In: DAVID, Raul. Escamoteados na Lei. União Endiama: Porto do Lobito, 1990.

CASTELO, Cláudia. Passagens para África. O Povoamento de Angola e Moçambique com Naturais da Metrópole. Porto: Edições Afrontamento, 2007. 
CHAGAS, Ledson Oliveira. A construção da angolanidade através da comunicação audiovisual. In: CONGRESSO REGIONAL DE CIÊNCIAS DA COMUNICAÇÃO - INTERCOM NORDESTE, 11., 2009, Teresina. Anais... Teresina: INTERCOM, 2009.

CONCEIÇÃO NETO, Maria da. In Town and Out of Town: A Social History of Huambo (Angola), 1902-1961. 2012. Thesis (PhD)-Department of History, School of Oriental and African Studies, University of London, London, 2012.

. Breve Introdução histórica. In: MEDINA, Maria do Carmo. Processos políticos da luta pela independência. Luanda: Faculdade de Direito UAN 2013. p. 15-30.

.Angola no Século XX (até 1974). In: ALEXANDRE, Valentim. O Império Africano (séculos XIX e XX). Lisboa: Edições Colibri, 2000. p. 175-196.

CORREIA, Fernando. Américo Boavida. Tempo e Memória (1923-1968). 1. ed. Luanda Instituto Nacional do Livro e do Disco, 2009.

CRUZ, Elizabeth Ceita Vera. O Estatuto do Indigenato e a legalização da discriminação na colonização portuguesa: o caso de Angola. Lisboa: Novo Imbondeiro, 2005.

DAVID, Raul. Ekaluko Lyakwafeka: brado patriótico. Luanda: União dos Escritores Angolanos, 1988.

. Crónicas de ontem para ouvir e contar. Porto: Edições Asa, União dos Escritores Angolanos, 1989. 1990.

. Escamoteados na lei. Luanda; Endiama: União dos Escritores Angolanos, . Colonizados e Colonizadores. Porto: Edições 70, 1984.

FERREIRA, Manuel. Literaturas africanas de expressão portuguesa. Lisboa: Biblioteca Breve; Instituto de Cultura e Língua Portuguesa, 1986. 2 v.

FENTRESS, James; WICKMAN, Chris. Memória social. Lisboa: Teorema, 1994.

FREUDENTHAL, Aida. A Baixa de Cassange: algodão e revolta. Revista Internacional de Estudos Africanos, Lisboa, n. 18-22, p. 245-283, 1995-1999.

GRAMSCI, Antonio. Cadernos do Cárcere. v. 2. Rio de Janeiro: Civilização Brasileira, 2000.

. Os intelectuais e a organização da cultura. Rio de Janeiro: Civilização Brasileira, 1982. 
HALBWACHS, Maurice. A memória coletiva. São Paulo: Centauro, 2006.

HAMPATÉ BÂ, A. A tradição viva. In: KI-ZERBO, Joseph (Coord.). História Geral da África I: Metodologia e pré-história da África. São Paulo: Cortez, 2010. HENRIQUES, Isabel Castro. Percursos da modernidade em Angola: dinâmicas comerciais e transformações sociais no século XIX. Lisboa: Instituto de Investigação Científica Tropical, 1997.

HERNANDEZ, Leila Leite. A África na sala de aula: visita a história contemporânea. São Paulo: Selo Negro, 2008.

LABAN, Michel. "Estória de família”, de Luandino Vieira (1972: "o que se mistura, separa”). In: GALVES, Charlote et al. África-Brasil: caminhos da língua portuguesa. Campinas: Editora da Unicamp, 2009. p. 115-127.

. Angola: encontro com escritores. Porto: Fundação Eng. António de Almeida, 1991.

LE CALLENNEC, Sophie. Os caminhos da emancipação In: M’BOKOLO, Elikia. África Negra: História e civilizações. Tomo 2 (do século XIX aos novos dias). Lisboa: Colibri, 2007. p. 455-546.

LOPES DE SÁ, Ana Lúcia. A Ruralidade na Narrativa Angolana do Século XX: Elemento de Construção da Nação. 2009. Tese (Doutoramento em Sociologia)Universidade da Beira Interior, Covilhã, 2009.

MATA, Inocência. Literatura e política em Angola, hoje: uma leitura da produção ficcional contemporânea. Matraga, Rio de Janeiro, v. 19, n. 31, p. 25-44, jul./dez. 2012.

MATEUS, Dalila Cabrita; MATEUS, Álvaro. Purga em Angola. Lisboa: Edições ASA, 2007.

MATEUS, Dalila Cabrita. A luta pela independência: a formação das elites fundadoras da FRELIMO, MPLA e PAIGC. Mem Martins: Inquérito, 1999.

M’BOKOLO, Elikia. Capítulo V: Idade de ouro ou crepúsculo da colonização, 1910-1940 In: . África negra: História e civilizações. t. 2. 2. ed. Lisboa: Colibri, 2012.

MEMMI, Albert. Retrato do colonizado precedido pelo retrato do colonizador. 3. ed. Rio de Janeiro: Paz e Terra, 1989.

MENDES, Afonso. A Huíla e Moçâmedes: considerações sobre o trabalho indígena. Lisboa: Junta de Investigações do Ultramar, 1958. 
MESSIANT, Christine. L'Angola post-colonial: Sociologie d'une oléocratie, Paris: Karthala, 2009.

MESSIANT, Christine. Luanda (1945-1961): colonisés, société coloniale et engagement nationaliste. In: CAHEN, Michel (Org). Vilas et cidades: Bourgs et villes en Afrique Lusophone. Paris: Laboratoire Tiers-Monde/Afrique, 1989. p. 125-199.

MESTRE, David. Recensão crítica a "Cantares do Nosso Povo", de Raul David. Colóquio/Letras, Lisboa, n. 87, p. 104-105, set. 1985.

MOREIRA, Adriano. As elites das províncias portuguesas de Indigenato (Guiné, Angola, Moçambique. Garcia de Orta, v. 4, n. 2, p. 159-190, 1956.

MORREU escritor angolano Raul David. AngoNotícias, 22 fev. 2005. Disponível em: $\langle$ http://www.angonoticias.com/artigos/item/3907/morreu-angolano-rauldavid >. Acesso em: 23 jun. 2016.

MOURÃO, Fernando Augusto Albuquerque. Continuidades e descontinuidades de um processo colonial através de uma leitura de Luanda. São Paulo: terceira margem, 2006.

. Configuração dos núcleos humanos de Luanda, do século XVI ao século XX. In: SEMINÁRIO ENCONTRO DE POVOS E CULTURAS EM ANGOLA, 3-6 abr. 1995, Luanda. Atas... Luanda: Arquivo Histórico Nacional de Angola, 1997.

MPLA consternado com morte do escritor Raúl David. ANGOP, 21 fev. 2005. Disponível em: <http://www.angop.ao/angola/pt_pt/noticias/politica/2005/1/8/ MPLA-consternado-com-morte-escritor-Raul-David,cdf2c41e-7505-4ada-9b89-07 feef7fa7df.html>. Acesso em: 23 jun. 2016.

NASCIMENTO, Washington Santos. Gentes do Mato: os "novos assimilados" em Luanda. 2013. Tese (Doutorado)-Faculdade de Filosofia, Letras e Ciências Humanas, Universidade de São Paulo, São Paulo, 2013.

PADILHA, Laura Cavalcante. Colonialidade e literatura em Angola - do enfrentamento às novas cartografias. In: DELGADO, Ignácio G. et al. (Org.). Vozes (além) da África. Juiz de Fora: EDUFJF, 2006. p. 73-88.

PRATT, Mary Louise. Os olhos do império: relatos de viagens e transculturação. Bauru: Edusc, 1999.

PRIORE, Mary Del. Biografia: quando o indivíduo encontra a história. Topoi, v. 10, n. 19, p. 7-16, dez. 2009. 
SANTIAGO, Silviano. O entre-lugar no discurso latino-americano. In:

Uma literatura nos trópicos. 2 ed. Rio de Janeiro: Rocco, 2000. p. 9-26.

SEBASTIÃO, Adriano. Dos campos de algodão aos dias de hoje. Luanda: Edição do Autor, 1993.

Recebido em: 24/04/2016

Aprovado em: 07/08/2016 